\title{
Characterization of the taste compounds in 20 pungent spices by high-performance liquid chromatography
}

\author{
Yan Huang ${ }^{1} \cdot$ Wen Duan $^{1} \cdot$ Junfei Xiao ${ }^{1} \cdot$ He Liu $^{1} \cdot$ Chenchen Zhou $^{1} \cdot$ Yuyu Zhang ${ }^{1}$ (D $\cdot$ Yizhuang Tang $^{1} \cdot$ Baoguo Sun $^{1}$. \\ Zhanming $\mathrm{Li}^{2}$
}

Received: 11 March 2020 / Accepted: 29 November 2020 / Published online: 11 December 2020

(c) The Author(s) 2020

\begin{abstract}
High-performance liquid chromatography was used to determine the important taste compounds in 20 pungent spices commonly used in food, including seventeen free amino acids, four 5 '-nucleotides and twelve organic acids. The equivalent umami concentration (EUC) and taste activity value (TAV) of the analyzed samples were calculated. The results showed that the content of total free amino acids ranged from 0.57 to $46.67 \mathrm{~g} / \mathrm{kg}$ in 20 pungent spices. The content of total free amino acids in horseradish was the highest. The content of total 5'-nucleotides ranged from 0.80 to $4.30 \mathrm{~g} / \mathrm{kg}$, and chive contains the highest 5'-nucleotide content. Inosine 5'-monophosphate was detected in all 20 pungent spices. The content of total organic acids ranged from 9.37 to $339.58 \mathrm{~g} / \mathrm{kg}$. The total organic acids content of fieldmint was the highest $(339.58 \mathrm{~g} / \mathrm{kg})$. Oxalic acid was detected in 18 pungent spices, except white pepper and chilli. The EUC of fieldmint ( $37.1 \mathrm{~g} \mathrm{MSG} / 100 \mathrm{~g}$ ) was the highest in all 20 pungent spices, followed with peppermint (24.5 g MSG/100 g), and horseradish (18.4 g MSG/100 g). The TAVs of malic acid, lactic acid and 5'-AMP were higher than 1 in more than 10 spices. Lactic acid were higher than 1 in 13 spices, implying these compounds contributed greater to the flavor of pungent spices. The results of this work will provide references for the application value of pungent spices.
\end{abstract}

Keywords Pungent spices $\cdot$ Free amino acid $\cdot$ Organic acid $\cdot 5^{\prime}$-Nucleotide $\cdot$ Flavor

\section{Introduction}

Spices are plant roots, leaves, stems, buds, seeds, or their extracts with stimulating fragrance that endow food with flavor, enhance appetite, and help food digestion and absorption [1]. GB/T 21725-2017 is a national standard made by China, which was released in November 2017. This national standard includes the classification method and definition of the spices. Spices are classified into three categories according to their characteristic flavor: strong fragrance, pungent, and elegant spices. Pungent spices are natural spice products with acrid taste and pungent odor. Their major flavor components include sulfur or amide compounds. Spices,

Yuyu Zhang

zhangyuyu@btbu.edu.cn

$1 \quad$ Beijing Key Laboratory of Flavor Chemistry, Beijing Technology and Business University, Beijing 100048, China

2 School of Grain Science and Technology, Jiangsu University of Science and Technology, Zhenjiang 212004, People's Republic of China with strong flavor characteristics, are widely used in the food industry, especially the Chinese cuisine. Adding spice can also change the food texture property and further affect the flavor perception during oral processing [2,3]. According to acceptability scores of consumers, the addition of spice-complexs, ginger and nutmeg can lower the scores of descriptors, such as rancid and off-flavor/odor [4]. The addition of spices can improve the overall taste of foods. Moreover, different spices have variable flavor characteristics and functional properties due to their differential flavor compounds.

Currently, many studies have been conducted to explore the importance of spices to dishes. Wang et al. [5] determined the taste components of beef soup with the addition of spices. The results showed that spices were beneficial for the release of flavor amino acids and increased its equivalent umami concentration (EUC). The EUC (154.5 gMSG/100 g) of fried beef packaged with spices was significantly higher than that of normal packaged fried beef (124.3 gMSG/100 g) [6]. Spices had a strong flavor enhancement effect, which was closely related to the flavor components 
in the spices. Yoshihisa et al. [7] detected sulfur compounds in seven Allium spices by HPLC, and the results suggested that isoalliin was the major flavor precursor. Zhang et al. [8] studied the flavor of allium after frying, and found the contents of furans and furanones, sulfur-containing compounds, aldehydes and alcohols increased sharply according to SAFE-GC-MS analysis. Therefore, gaining a deep understanding of the chemical compositions and the taste-active compounds in spices will make a meaningful contribution and could provide guidance for the standardization of spices application and further processing. In our previous work, the taste components of strong fragrance spices and elegant spices have been detected $[9,10]$. Therefore, the taste components of pungent spices should be studied to complete the taste database of spices.

The sample pretreatment and detection technology are very important for taste compounds research in pungent spices. Recently, several sample pretreatment techniques for the determination of organic and inorganic compounds have been developed, such as microextraction based on deep eutectic solvents [11-14], continuous sample drop flowbased microextraction [15], dispersive liquid-liquid microextraction based on the solidification of the floating organic drop [16-18], and solid phase extraction combined with dispersive liquid-liquid microextraction [19]. Among them, liquid-liquid extraction is a convenient and widely used pretreatment method. Taste compounds determine the flavor and taste of food, such as free amino acids, 5'-nucleotides, and organic acids are ingredients used during food processing. [20]. And they were usually determined by high-performance liquid chromatography (HPLC) [21, 22].Organic acids play an essential role in many important reactions in organisms. Fujita et al. [23] studied the effects of organic acids on the flavor characteristics of Tricholoma giganteum and detected the presence of acetic, succinic, oxalic, malic, pyroglutamic, and fumaric acids in Tricholoma giganteum samples. Moreover, succinic and oxalic acids were the predominant organic acids in Tricholoma giganteum and accounted for $63.8 \%$ of its total organic acid content. According to the statistical analysis of literature, HPLC was the mainstream analysis method for taste compounds. Based on previous researchs, in this study, the quantitative analysis of main taste compounds of 20 pungent spice was carried out by HPLC. For the sample pretreatment, organic solvent combined with ultrasonic method were used.

The aims of this work were to identify the flavor components in 20 pungent spices and provide a theoretical basis for the applications of these spices. The high-performance liquid chromatography was used to determine free amino acids, 5 '- nucleotides, and organic acids in 20 pungent spices. The equivalent umami concentration (EUC) and taste activity value (TAV) of the analyzed samples were calculated. The EUC based on cluster analysis was used to classify 20 pungent spices to distinguish their umami levels. The results of this work will provide references for the application value of pungent spices when they are added to various raw materials as auxiliary ingredients during food processing.

\section{Materials and methods}

\section{Reagents}

Analytical grade inosine $5^{\prime}$-monophosphate (5'IMP), adenosine 5'-monophosphate (5'-AMP), guanosine $5^{\prime}$-monophosphate (5'-GMP), and cytidine 5 '-monophosphate (5'-CMP) were purchased from SigmaAldrich (St. Louis, MO, USA). Analytical grade malic, citric, lactic, succinic, oxalic, tartaric, formic, acetic, propionic, pyruvic, ascorbic, and pyroglutamic acids were acquired from Sinopharm Chemical Reagent Co. (Shanghai, China). Analytical grade monopotassium phosphate $\left(\mathrm{KH}_{2} \mathrm{PO}_{4}\right)$, sodium dihydrogen phosphate dodecahydrate $\left(\mathrm{Na}_{2} \mathrm{HPO}_{4} \cdot 12 \mathrm{H}_{2} \mathrm{O}\right)$, and sodium borate decahydrate $\left(\mathrm{Na}_{2} \mathrm{~B}_{4} \mathrm{O}_{7} \cdot 10 \mathrm{H}_{2} \mathrm{O}\right)$ mobile phase buffer salts were purchased from Alfa Aesar (Ward Hill, MA, USA). HPLC-grade methanol and acetonitrile (ACN) were procured from Fisher Scientific (Shanghai, China), Durashell AA analytical kits were obtained from Tianjin Bona Agel Technology Co., Ltd. (Tianjin, China), ultra-pure water was supplied by Hangzhou Wahaha Group Co., Ltd. (Hangzhou, China), and analytical reagent grade sulfosalicylic acid was from Biochemical Technology Co., Ltd. (Shanghai, China).

\section{Pungent spices}

All the 20 pungent spices in Table 1 were purchased from Yonghui Supermarket (Beijing, China). Fresh garlic, welsh onion, chive, ginger, onion, peppermint, and fieldmint samples were immediately crushed into mud and store at -20 ${ }^{\circ} \mathrm{C}$ for use. The other 13 samples including white mustard, white pepper, litsea, prickly ash, asafoetida, lemongrass, villosum, winter leek, greater galanga, long pepper, black mustard, chilli and horseradish were placed on the table, dried naturally, powdered subsequently, and then the powder was finally obtained. Samples $(5 \mathrm{~g})$ were added to $15 \mathrm{~mL}$ of solvent (50\% ethanol and 50\% ultra-pure water) and ultrasonicated at $40 \mathrm{~W}$ for $15 \mathrm{~min}$, and then centrifuged at $10,000 \mathrm{rpm}$ for $10 \mathrm{~min}$ at $4{ }^{\circ} \mathrm{C}$. The supernatant was filtered through filter paper (No. 4), and the residue was re-extracted twice by following the aforementioned steps. Subsequently, the supernatant was mixed and diluted to $50 \mathrm{~mL}$ to obtain test solution I, which was used to detect organic acids and 5 '-nucleotides $[9,10]$. Test solution I $(2 \mathrm{~mL})$ was added to $1 \mathrm{~mL}$ of sulfosalicylic acid, and then diluted to $5 \mathrm{~mL}$ with 
Table 1 Information of 20 pungent spices

\begin{tabular}{|c|c|c|c|c|c|}
\hline Number & Name & Moisture content & Botanical name & Part & Place of origin \\
\hline 1 & Garlic & $64.57 \pm 1.63$ & Allium sativum $\mathrm{L}$. & bulb & Shandong Province \\
\hline 2 & Welsh onion & $86.93 \pm 2.79$ & Allium fistulosum $\mathrm{L}$. & plant & Shandong Province \\
\hline 3 & Chive & $91.57 \pm 0.92$ & Allium schoenopasum $\mathrm{L}$. & leaf & Shandong Province \\
\hline 4 & White mustard & $5.63 \pm 0.09$ & Sinapis alba $\mathrm{L}$ & seed & Jiangsu Province \\
\hline 5 & White pepper & $11.04 \pm 0.01$ & Piper nigrum $\mathrm{L}$. & fruit & Guangxi Province \\
\hline 6 & Litsea & $7.08 \pm 0.04$ & Litsea pungens Hemsl. & fruit & Guizhou Province \\
\hline 7 & Prickly ash & $7.93 \pm 0.01$ & Zanthoxylum bungeanum Maxim. & fruit & Gansu Province \\
\hline 8 & Asafoetida & $6.28 \pm 0.35$ & Ferula assa-foetida $\mathrm{L}$. & rhizome & Xinjiang Province \\
\hline 9 & Ginger & $9.36 \pm 0.01$ & Gingiber officinale Roscoe. & rhizome & Guangxi Province \\
\hline 10 & Onion & $89.05 \pm 0.53$ & Allium cepa $\mathrm{L}$. & bulb & Shandong Province \\
\hline 11 & Lemongrass & $5.31 \pm 0.02$ & Cymbopogon citrates (DC.) Stapf. & leaf & Guangxi Province \\
\hline 12 & Villosum & $9.62 \pm 0.13$ & Amomum villosum Lour. & fruit & Guangxi Province \\
\hline 13 & Winter leek & $6.70 \pm 0.12$ & Allium porrum $\mathrm{L}$. & leaf, bulb & Jiangsu Province \\
\hline 14 & Greater galanga & $8.09 \pm 0.14$ & Alpinia galanga (L.) Willd. & rhizome & Guangxi Province \\
\hline 15 & Long pepper & $10.03 \pm 0.06$ & Piper longum $\mathrm{L}$. & fruit & Guangxi Province \\
\hline 16 & Black mustard & $4.75 \pm 0.18$ & Brassica nigra (L.) W.D.J.Koch. & seed & India Country \\
\hline 17 & Peppermint & $8.97 \pm 0.25$ & Mentha $\times$ piperita $\mathrm{L}$. & leaf, bud & Turkey Country \\
\hline 18 & Chilli & $5.99 \pm 0.10$ & Capsicum frutescens $\mathrm{L}$. & fruit & Chongqing City \\
\hline 19 & Horseradish & $3.73 \pm 0.11$ & $\begin{array}{l}\text { Armoracia rusticana P.Gaertn.B.Meyei } \\
\text { et Scherb. }\end{array}$ & root & Shandong Province \\
\hline 20 & Fieldmint & $87.91 \pm 1.07$ & Mentha arvensis $\mathrm{L}$. & leaf, bud & Shanghai City \\
\hline
\end{tabular}

$0.01 \mathrm{M} \mathrm{HCl}$ to obtain test solution II, which was used to detect free amino acids [9, 10].

\section{Detection conditions}

A Thermo U3000 (Thermo Scientific, Waltham, MA, USA) ultra-performance liquid chromatography (UPLC) system was employed to detect the content of organic acids in the samples. The detection conditions were as follows: chromatographic column, VenusilMP C18 (4.6 mm $\times 250 \mathrm{~mm}$, $5 \mu \mathrm{m}$ ); column temperature, $25{ }^{\circ} \mathrm{C}$; diode array detector; detection wavelength, $205 \mathrm{~nm}$; mobile phase, buffer salt I (0.01 $\left.\mathrm{M} \mathrm{KH}_{2} \mathrm{PO}_{4}, \mathrm{pH} 2.8\right)$. The mobile phase consisted of methanol:buffer salt I (5:95, (v/v)) with equivalent elution. The injection volume and flow rate were $20 \mu \mathrm{L}$ and $1.0 \mathrm{~mL} /$ min, respectively [24].

A Thermo U3000 UPLC system was employed to detect the content of 5'-nucleotide in the samples. The detection conditions were as follows: chromatographic column, VenusilMPC18 (4.6 mm $\times 250 \mathrm{~mm}, 5 \mu \mathrm{m})$; column temperature, $25{ }^{\circ} \mathrm{C}$; diode array detector; detection wavelength, $254 \mathrm{~nm}$; mobile phase, buffer salt II (0.05 $\left.\mathrm{M} \mathrm{KH}_{2} \mathrm{PO}_{4}\right)$. The mobile phase consisted of methanol:buffer salt II $(5: 95$, (v/v)) with equivalent elution. The injection volume and flow rate were $20 \mu \mathrm{L}$ and $1.0 \mathrm{~mL} / \mathrm{min}$, respectively.

An Agilent 1260 (Agilent Corp., Karlsruhe, Germany) HPLC system was employed to determine the content of free amino acid in the samples. The detection conditions were as follows: chromatographic column, Venusil Durashell AA (4.6 mm $\times 150 \mathrm{~mm}, 3 \mu \mathrm{m}$ ); column temperature, $45^{\circ} \mathrm{C}$; $\mathrm{UV}$ detector; detection wavelengths, 338 and $262 \mathrm{~nm}$; mobile phases: mobile phase A $\left(0.03 \mathrm{M} \mathrm{Na}_{2} \mathrm{HPO}_{4} \cdot 12 \mathrm{H}_{2} \mathrm{O}\right.$ and $0.02 \mathrm{M} \mathrm{Na}_{2} \mathrm{~B}_{4} \mathrm{O}_{7} \cdot 10 \mathrm{H}_{2} \mathrm{O} ; \mathrm{pH}$ was adjusted to 8.2 ) and mobile phase $\mathrm{B}$ ( $45 \%$ methanol, $45 \%$ acetonitrile, and $10 \%$ ultrapure water); the elution gradient was as follows: 0-6 min 6-10\% B, 6-8 min $10 \% \mathrm{~B}, 8-10 \min 10-16 \% \mathrm{~B}, 10-23 \min 16-40 \%$ B, 23-30 min 40-50\% B, 30-31 min 50-100\% B, 31-34 min $100 \% \mathrm{~B}, 35-38 \mathrm{~min} 6 \% \mathrm{~B}$; the flow rate, injection volume, and detection time were $1.6 \mathrm{~mL} / \mathrm{min}, 20 \mu \mathrm{L}$, and $38 \mathrm{~min}$, respectively.

\section{Quantitative analysis of the standard curve}

The external standard method was used for the quantitative analysis of 5'-nucleotides. The standard curves of the $5^{\prime}$-nucleotides are presented in Table 2. First, $0.010 \mathrm{~g}$ of 5'-AMP, 5'-IMP, 5'-GMP, and 5'-CMP were weighed and subsequently dissolved in ultra-pure water, and then transfer the mixture to a $100 \mathrm{~mL}$ capacity bottle to obtain the standard reserve solutions with concentrations of $0.100 \mathrm{mg} /$ $\mathrm{mL}$. Afterward, the standard solutions were diluted to 0.100 , $0.050,0.020,0.010,0.005,0.002$, and $0.001 \mathrm{mg} / \mathrm{mL}$ gradient standard solutions. The standard curve of each flavor 
Table 2 Standard curves of organic acids and nucleotides in 20 pungent spices

\begin{tabular}{lllll}
\hline Compounds & Standard curve & $R^{2}$ & LOD $(\mu \mathrm{g} / \mathrm{mL})$ & LOQ $(\mu \mathrm{g} / \mathrm{mL})$ \\
\hline Malic acid & $y=0.100 x+0.052$ & 0.999 & 0.020 & 0.050 \\
Citric acid & $y=0.067 x+0.079$ & 0.999 & 0.004 & 0.006 \\
Lactic acid & $y=0.248 x+0.108$ & 0.995 & 0.001 & 0.007 \\
Succinic acid & $y=0.185 x-0.080$ & 0.997 & 0.008 & 0.015 \\
Oxalic acid & $y=0.017 x-0.052$ & 0.996 & 0.001 & 0.003 \\
Tartaric acid & $y=0.058 x-0.142$ & 0.993 & 0.010 & 0.033 \\
Formic acid & $y=0.066 x-0.272$ & 0.998 & 0.005 & 0.016 \\
Acetic acid & $y=0.182 x-0.007$ & 0.999 & 0.005 & 0.016 \\
Propionic acid & $y=0.386 x-3.305$ & 0.996 & 0.006 & 0.019 \\
Pyruvic acid & $y=0.019 x-0.003$ & 0.998 & 0.002 & 0.005 \\
Ascorbic acid & $y=0.048 x-0.051$ & 0.994 & 0.001 & 0.003 \\
Pyroglutamic acid & $y=0.009 x-0.041$ & 0.991 & 0.002 & 0.005 \\
5'-AMP & $y=0.0091 x-0.0099$ & 0.995 & 0.020 & 0.044 \\
5'-IMP & $y=0.0061 x+0.0020$ & 0.999 & 0.050 & 0.200 \\
5'-GMP & $y=0.0074 x+0.0020$ & 0.999 & 0.090 & 0.320 \\
5'-CMP & $y=0.0082 x-0.0034$ & 0.993 & 0.060 & 0.210 \\
\hline
\end{tabular}

nucleotide was obtained by plotting its chromatographic peak area vs. its concentration.

The external standard method was used for the quantitative analysis of the organic acids. The standard curves of the organic acids are depicted in Table 2. Twelve standard acids, viz. malic, citric, lactic, succinic, oxalic, pyruvic, tartaric, formic, acetic, propionic, ascorbic, and pyroglutamic, were dissolved in ultra-pure, and then transfer the mixture to a capacity bottle to obtain the standard reserve solutions with concentrations of $4 \mathrm{mg} / \mathrm{mL}$. These solutions were subsequently diluted to $2.00,0.80,0.40,0.20,0.08,0.02$ and $0.01 \mathrm{mg} / \mathrm{mL}$. The standard curves of the organic acids were obtained by plotting the concentrations of the organic acids vs. the areas of their chromatographic peaks.

The free amino acids were quantified using the internal standard method. The standards, solvents for washing the needles, and derivative reagents were included in the Durashell AA reagent analysis kits. The calibration curves were obtained by comparing the amino acid peak areas with the norvaline (Nva) and sarcosine (Sar) peak areas of the internal standard solution. The concentration of the Cys-Cys standard solution was $0.014-0.341 \mathrm{M}$ and those of the other amino acids ranged from 0.027 to $0.682 \mathrm{M}$.

The 20 pungent spices including fresh and dried spices, and the moisture content were measured. The content of dry weight basis was transformed based on the moisture content and the sample weight content. Each sample was conducted in triplicate.

\section{Statistical analysis}

Statistical analysis of the data was performed using the Microsoft Excel and SPSS (version 19.0, SPSS Inc.,
Chicago, IL, USA) software. All data were presented as average values \pm standard deviations.

\section{Results and analysis}

\section{Analysis of free amino acids}

Free amino acids play important roles in the growth and development of organisms [25, 26] and improve food flavor [27, 28]. According to Kim et al. [29], free amino acids can be divided into four categories: umami (aspartic acid (Asp), glutamic acid (Glu)), sweet (serine (Ser), alanine (Ala), glycine (Gly), threonine (Thr)), bitterness (arginine (Arg), histidine (His), tyrosine (Tyr), leucine (Leu), valine (Val), methionine (Met), isoleucine (Ile), phenylalanine (Phe), lysine (Lys), proline (Pro)), and tasteless (cysteine (Cys)).

The proportion of three types of free amino acids (umami, sweet, and bitter) in 20 pungent spices were shown in Fig. 1 and the content of taste compounds were shown in Table 3. The content of bitter free amino acids in eight spices were more than $50.0 \%$. The proportion of bitter amino acids in litsea $(88.7 \%)$ was the highest among 20 pungent spices, followed by horseradish $(86.3 \%)$ and garlic $(82.9 \%)$. Horseradish has highest content of total free amino acids $(46.67 \mathrm{~g} / \mathrm{kg})$ because of its higher total bitter amino acids content $(40.26 \mathrm{~g} / \mathrm{kg})$, especially with the content of Arg $(24.84 \mathrm{~g} / \mathrm{kg})$. The bitter free amino acids are rich in pungent spices, which is similar to strong fragrance spices [9] and elegant spices [10]. The proportion of umami free amino acids in 3 spices were more than $50 \%$, including white mustard $(58.7 \%)$, black mustard $(67.6 \%)$, and peppermint $(75.1 \%)$. The total content 


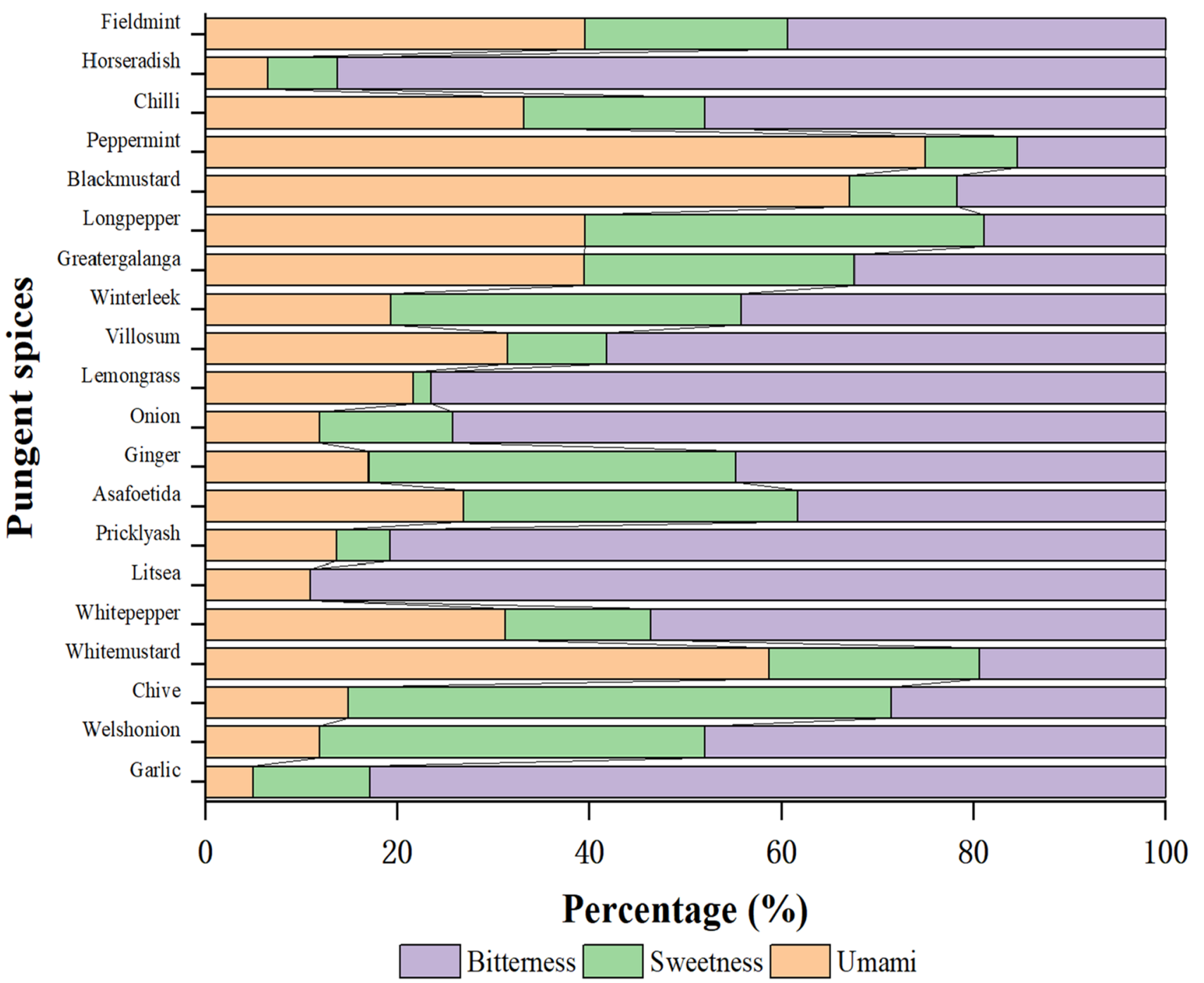

Fig. 1 The proportion of three types of free amino acids in 20 pungent spices

of umami amino acids in peppermint $(7.87 \mathrm{~g} / \mathrm{kg})$ was the highest among 20 pungent spices with the content of Glu in $6.45 \mathrm{~g} / \mathrm{kg}$. Daniel et al. [30] reported that Glu content accounted for $89.0 \%$ of the umami components in duck sauce with the addition of spices. So we conclude the addition of spices contributes to the release of umami amino acids from meat. Also, the Asp and Glu are the main umami amino acids [31], which contributes to the main umami taste of food. Only Asp was detected in all 20 pungent spices, and onion has the highest Asp content with $2.56 \mathrm{~g} / \mathrm{kg}$, fieldmint has the highest Glu content with $2.16 \mathrm{~g} / \mathrm{kg}$. The proportion of sweet free amino acids in chive $(55.1 \%)$ was more than $50 \%$. Eight free amino acids were widely found in 20 pungent spices. Three free amino acids including Ala, Arg, and Val were detected in 19 pungent spices. Four free amino acids were detected in 17 pungent spices, including Glu, Ser, Lys, and Pro.

\section{Analysis of organic acids}

The limit of detection and quantification were calculated as follows: $\mathrm{LOD}=3.3 \sigma / b$ and $\mathrm{LOQ}=10 \sigma / b$, respectively, where $\sigma$ is the y-intercept standard deviation and $b$ is the slope of the linear regression [32]. The obtained LOD and LOQ values are summarized in Table 2.

The standard curves of 12 organic acids were shown in Table 2. The organic acid contents in 20 pungent spices were shown in Table 3. Organic acids appear to play an important role in taste. The content of total organic acids in fieldmint was the highest $(339.58 \mathrm{~g} / \mathrm{kg})$ among 20 pungent spices. It is reported that organic acids and their sodium salt have effects of enhancing flavor, and sodium succinate has an excellent umami enhancement [24]. The succinic acid could increase the threshold of taste components by 30 times [33]. The content of succinic acid in welsh onion $(83.53 \mathrm{~g} / \mathrm{kg})$ 
Table 3 The content of free amino acids, 5'-nucleotides, organic acids in 20 pungent spices

\begin{tabular}{|c|c|c|c|c|c|c|c|}
\hline \multirow[t]{2}{*}{ Compounds } & \multicolumn{7}{|c|}{ Content (g/kg dry wt) } \\
\hline & Garlic & Welsh onion & Chive & White mustard & White pepper & Litsea & Prickly ash \\
\hline \multicolumn{8}{|l|}{ Free amino acids } \\
\hline \multicolumn{8}{|l|}{ Umami } \\
\hline Asp & $1.67 \pm 0.08$ & $1.03 \pm 0.22$ & $0.84 \pm 0.09$ & $0.69 \pm 0.00$ & $0.22 \pm 0.00$ & $0.06 \pm 0.00$ & $1.24 \pm 0.00$ \\
\hline Glu & $0.17 \pm 0.01$ & nd & nd & $1.95 \pm 0.00$ & $0.12 \pm 0.00$ & nd & $0.16 \pm 0.00$ \\
\hline Total & $1.84 \pm 0.08$ & $1.03 \pm 0.22$ & $0.84 \pm 0.09$ & $2.64 \pm 0.00$ & $0.35 \pm 0.00$ & $0.06 \pm 0.00$ & $1.4 \pm 0.00$ \\
\hline \multicolumn{8}{|l|}{ Sweetness } \\
\hline Ser & $2.49 \pm 0.11$ & $1.26 \pm 0.28$ & $1.43 \pm 0.06$ & $0.26 \pm 0.00$ & $0.07 \pm 0.00$ & nd & $0.21 \pm 0.00$ \\
\hline Ala & $1.16 \pm 0.05$ & $2.21 \pm 0.18$ & $1.79 \pm 0.20$ & $0.59 \pm 0.00$ & $0.07 \pm 0.00$ & nd & $0.2 \pm 0.00$ \\
\hline Gly & $0.14 \pm 0.01$ & $0.16 \pm 0.03$ & nd & $0.04 \pm 0.00$ & nd & nd & $0.17 \pm 0.00$ \\
\hline Thr & $0.65 \pm 0.03$ & nd & nd & $0.07 \pm 0.00$ & $0.03 \pm 0.00$ & nd & nd \\
\hline Total & $4.44 \pm 0.20$ & $3.63 \pm 0.49$ & $3.23 \pm 0.26$ & $0.97 \pm 0.00$ & $0.17 \pm 0.00$ & nd & $0.58 \pm 0.00$ \\
\hline \multicolumn{8}{|l|}{ Bitterness } \\
\hline Arg & $14.56 \pm 0.67$ & $0.79 \pm 0.07$ & $0.60 \pm 0.01$ & $0.25 \pm 0.00$ & $0.10 \pm 0.00$ & nd & $2.38 \pm 0.00$ \\
\hline His & $2.97 \pm 0.14$ & nd & nd & nd & nd & $0.06 \pm 0.00$ & $0.73 \pm 0.00$ \\
\hline Tyr & $2.06 \pm 0.10$ & $0.39 \pm 0.04$ & $0.36 \pm 0.02$ & nd & $0.06 \pm 0.00$ & nd & $0.02 \pm 0.00$ \\
\hline Leu & $1.72 \pm 0.08$ & $0.47 \pm 0.10$ & $0.36 \pm 0.02$ & $0.03 \pm 0.00$ & $0.19 \pm 0.00$ & $0.02 \pm 0.00$ & nd \\
\hline Val & $1.70 \pm 0.08$ & $0.24 \pm 0.05$ & $0.24 \pm 0.03$ & $0.02 \pm 0.00$ & $0.06 \pm 0.00$ & $0.02 \pm 0.00$ & $0.03 \pm 0.00$ \\
\hline Met & $0.08 \pm 0.00$ & $0.63 \pm 0.04$ & nd & $0.34 \pm 0.00$ & $0.06 \pm 0.00$ & nd & $0.11 \pm 0.00$ \\
\hline Ile & $0.51 \pm 0.02$ & nd & nd & $0.04 \pm 0.00$ & nd & $0.37 \pm 0.00$ & $0.02 \pm 0.00$ \\
\hline Phe & $1.95 \pm 0.09$ & $0.24 \pm 0.05$ & nd & $0.10 \pm 0.00$ & $0.04 \pm 0.00$ & nd & $0.02 \pm 0.00$ \\
\hline Lys & $2.97 \pm 0.14$ & $0.39 \pm 0.04$ & $0.24 \pm 0.03$ & $0.03 \pm 0.00$ & $0.03 \pm 0.00$ & $0.03 \pm 0.00$ & $0.09 \pm 0.00$ \\
\hline Pro & $1.87 \pm 0.09$ & $1.11 \pm 0.04$ & nd & $0.06 \pm 0.00$ & $0.08 \pm 0.00$ & nd & $4.88 \pm 0.00$ \\
\hline Total & $30.38 \pm 1.4$ & $4.26 \pm 0.43$ & $1.79 \pm 0.10$ & $0.88 \pm 0.00$ & $0.62 \pm 0.00$ & $0.51 \pm 0.00$ & $8.28 \pm 0.00$ \\
\hline \multicolumn{8}{|l|}{ Tasteless } \\
\hline Cys-Cys & $0.08 \pm 0.00$ & $0.39 \pm 0.09$ & nd & nd & nd & nd & $0.09 \pm 0.00$ \\
\hline Total free amino acids & $36.74 \pm 1.32$ & $9.32 \pm 1.24$ & $5.86 \pm 0.45$ & $4.49 \pm 0.00$ & $1.14 \pm 0.00$ & $0.57 \pm 0.00$ & $10.34 \pm 0.00$ \\
\hline \multicolumn{8}{|l|}{ 5'-Nucleotides } \\
\hline 5'-CMP & $0.54 \pm 0.02$ & $0.08 \pm 0.02$ & $0.84 \pm 0.09$ & $0.01 \pm 0.00$ & $0.22 \pm 0.00$ & $0.16 \pm 0.00$ & nd \\
\hline 5'-GMP & $0.23 \pm 0.01$ & nd & nd & $0.12 \pm 0.00$ & $0.29 \pm 0.00$ & nd & $0.47 \pm 0.00$ \\
\hline 5'-IMP & $0.20 \pm 0.01$ & $0.24 \pm 0.05$ & $0.84 \pm 0.09$ & $0.36 \pm 0.00$ & $0.17 \pm 0.00$ & $0.04 \pm 0.00$ & $0.14 \pm 0.00$ \\
\hline 5'-AMP & nd & nd & $2.63 \pm 0.29$ & $0.03 \pm 0.00$ & $0.04 \pm 0.00$ & $0.51 \pm 0.00$ & nd \\
\hline Total $5^{\prime}$-nucleotides & $0.96 \pm 0.04$ & $0.32 \pm 0.07$ & $4.30 \pm 0.47$ & $0.52 \pm 0.00$ & $0.73 \pm 0.00$ & $0.71 \pm 0.00$ & $0.61 \pm 0.00$ \\
\hline \multicolumn{8}{|l|}{ Organic acids } \\
\hline Malic acid & $25.69 \pm 1.18$ & $20.76 \pm 4.53$ & nd & $6.36 \pm 0.01$ & nd & nd & $8.44 \pm 0.00$ \\
\hline Citric acid & nd & $21.95 \pm 1.79$ & nd & nd & nd & nd & nd \\
\hline Lactic acid & $29.23 \pm 1.35$ & $42.24 \pm 2.22$ & $112.28 \pm 12.33$ & nd & $9.94 \pm 0.00$ & $5.8 \pm 0.00$ & nd \\
\hline Succinic acid & nd & $83.53 \pm 5.24$ & nd & $5.56 \pm 0.01$ & $6.92 \pm 0.00$ & $5.38 \pm 0.00$ & $10.00 \pm 0.00$ \\
\hline Oxalic acid & $27.19 \pm 1.25$ & $10.03 \pm 2.19$ & $137.51 \pm 15.10$ & $0.59 \pm 0.00$ & nd & $4.41 \pm 0.00$ & $5.43 \pm 0.00$ \\
\hline Tartaric acid & nd & nd & nd & $9.13 \pm 0.01$ & nd & nd & $18.08 \pm 0.00$ \\
\hline Formic acid & $7.94 \pm 0.37$ & $42.79 \pm 2.35$ & nd & nd & nd & nd & $1.98 \pm 0.00$ \\
\hline Acetic acid & nd & nd & nd & $9.82 \pm 0.01$ & $5.11 \pm 0.00$ & nd & $7.09 \pm 0.00$ \\
\hline Propionic acid & nd & nd & nd & nd & nd & nd & nd \\
\hline Pyruvic acid & nd & nd & nd & nd & nd & nd & nd \\
\hline Ascorbic acid & nd & nd & nd & nd & nd & nd & $10.94 \pm 0.00$ \\
\hline Pyroglutamic acid & nd & nd & nd & nd & nd & $2.49 \pm 0.00$ & nd \\
\hline Total organic acids & $90.05 \pm 4.15$ & $221.29 \pm 18.33$ & $249.80 \pm 27.42$ & $31.47 \pm 0.03$ & $21.98 \pm 0.00$ & $18.08 \pm 0.01$ & $61.96 \pm 0.01$ \\
\hline
\end{tabular}


Table 3 (continued)

\begin{tabular}{|c|c|c|c|c|c|c|c|}
\hline Compounds & Asafoetida & Ginger & Onion & Lemongrass & Villosum & Winter leek & Greater galanga \\
\hline \multicolumn{8}{|l|}{ Free amino acids } \\
\hline \multicolumn{8}{|l|}{ Umami } \\
\hline Asp & $0.23 \pm 0.00$ & $0.71 \pm 0.00$ & $2.56 \pm 0.12$ & $0.15 \pm 0.00$ & $0.27 \pm 0.00$ & $0.21 \pm 0.00$ & $0.91 \pm 0.00$ \\
\hline Glu & $0.14 \pm 0.00$ & $0.38 \pm 0.00$ & $0.37 \pm 0.02$ & $0.10 \pm 0.00$ & $0.18 \pm 0.00$ & $0.57 \pm 0.00$ & $0.08 \pm 0.00$ \\
\hline Total & $0.37 \pm 0.00$ & $1.08 \pm 0.00$ & $2.93 \pm 0.14$ & $0.24 \pm 0.00$ & $0.44 \pm 0.00$ & $0.78 \pm 0.00$ & $0.99 \pm 0.00$ \\
\hline \multicolumn{8}{|l|}{ Sweetness } \\
\hline Ser & $0.05 \pm 0.00$ & $0.67 \pm 0.00$ & $2.29 \pm 0.11$ & nd & $0.11 \pm 0.00$ & $0.24 \pm 0.00$ & $0.49 \pm 0.00$ \\
\hline Ala & $0.28 \pm 0.00$ & $1.39 \pm 0.00$ & $0.46 \pm 0.02$ & $0.02 \pm 0.00$ & $0.03 \pm 0.00$ & $0.94 \pm 0.00$ & $0.17 \pm 0.00$ \\
\hline Gly & $0.11 \pm 0.00$ & $0.11 \pm 0.00$ & nd & nd & nd & $0.03 \pm 0.00$ & $0.01 \pm 0.00$ \\
\hline Thr & $0.04 \pm 0.00$ & $0.26 \pm 0.00$ & $0.64 \pm 0.03$ & nd & nd & $0.26 \pm 0.00$ & $0.02 \pm 0.00$ \\
\hline Total & $0.48 \pm 0.00$ & $2.44 \pm 0.00$ & $3.38 \pm 0.16$ & $0.02 \pm 0.00$ & $0.14 \pm 0.00$ & $1.47 \pm 0.00$ & $0.70 \pm 0.00$ \\
\hline \multicolumn{8}{|l|}{ Bitterness } \\
\hline Arg & $0.27 \pm 0.00$ & $0.60 \pm 0.00$ & $8.96 \pm 0.43$ & $0.03 \pm 0.00$ & $0.03 \pm 0.00$ & $0.38 \pm 0.00$ & $0.05 \pm 0.00$ \\
\hline His & nd & $0.11 \pm 0.00$ & $0.91 \pm 0.04$ & nd & nd & nd & $0.04 \pm 0.00$ \\
\hline Tyr & $0.03 \pm 0.00$ & $0.30 \pm 0.00$ & $0.73 \pm 0.04$ & $0.30 \pm 0.00$ & nd & $0.13 \pm 0.00$ & $0.01 \pm 0.00$ \\
\hline Leu & $0.05 \pm 0.00$ & $0.45 \pm 0.00$ & $0.91 \pm 0.04$ & nd & $0.02 \pm 0.00$ & $0.29 \pm 0.00$ & $0.03 \pm 0.00$ \\
\hline Val & nd & $0.41 \pm 0.00$ & $0.46 \pm 0.02$ & $0.23 \pm 0.00$ & $0.01 \pm 0.00$ & $0.24 \pm 0.00$ & $0.02 \pm 0.00$ \\
\hline Met & nd & $0.18 \pm 0.00$ & $0.73 \pm 0.04$ & $0.21 \pm 0.00$ & $0.10 \pm 0.00$ & $0.06 \pm 0.00$ & $0.50 \pm 0.00$ \\
\hline Ile & $0.03 \pm 0.00$ & $0.21 \pm 0.00$ & $0.18 \pm 0.01$ & nd & $0.15 \pm 0.00$ & $0.17 \pm 0.00$ & $0.01 \pm 0.00$ \\
\hline Phe & $0.03 \pm 0.00$ & $0.22 \pm 0.00$ & $0.37 \pm 0.02$ & nd & nd & $0.15 \pm 0.00$ & $0.02 \pm 0.00$ \\
\hline Lys & $0.05 \pm 0.00$ & $0.26 \pm 0.00$ & $1.46 \pm 0.07$ & nd & nd & $0.24 \pm 0.00$ & $0.02 \pm 0.00$ \\
\hline Pro & $0.05 \pm 0.00$ & $0.12 \pm 0.00$ & $3.20 \pm 0.16$ & $0.08 \pm 0.00$ & $0.50 \pm 0.00$ & $0.14 \pm 0.00$ & $0.10 \pm 0.00$ \\
\hline Total & $0.52 \pm 0.00$ & $2.86 \pm 0.00$ & $17.93 \pm 0.87$ & $0.86 \pm 0.00$ & $0.82 \pm 0.00$ & $1.79 \pm 0.00$ & $0.82 \pm 0.00$ \\
\hline \multicolumn{8}{|l|}{ Tasteless } \\
\hline Cys-Cys & nd & $0.10 \pm 0.00$ & nd & nd & nd & $0.05 \pm 0.00$ & $0.28 \pm 0.00$ \\
\hline Total free amino acids & $1.38 \pm 0.00$ & $6.48 \pm 0.00$ & $24.24 \pm 1.17$ & $1.12 \pm 0.00$ & $1.41 \pm 0.00$ & $4.09 \pm 0.00$ & $2.79 \pm 0.00$ \\
\hline \multicolumn{8}{|l|}{$5^{\prime}$-Nucleotides } \\
\hline 5'-CMP & $0.10 \pm 0.00$ & $0.04 \pm 0.00$ & nd & $0.33 \pm 0.00$ & $0.02 \pm 0.00$ & $0.18 \pm 0.00$ & $0.17 \pm 0.00$ \\
\hline 5'-GMP & $0.14 \pm 0.00$ & $0.09 \pm 0.00$ & nd & $0.06 \pm 0.00$ & nd & nd & $0.07 \pm 0.00$ \\
\hline 5'-IMP & $0.12 \pm 0.00$ & $0.15 \pm 0.00$ & $0.18 \pm 0.01$ & $0.11 \pm 0.00$ & $0.06 \pm 0.00$ & $0.79 \pm 0.00$ & $0.07 \pm 0.00$ \\
\hline 5'-AMP & nd & $0.50 \pm 0.00$ & nd & $0.02 \pm 0.00$ & nd & $0.61 \pm 0.00$ & $0.07 \pm 0.00$ \\
\hline Total 5'-nucleotides & $0.35 \pm 0.00$ & $0.78 \pm 0.00$ & $0.18 \pm 0.01$ & $0.52 \pm 0.00$ & $0.08 \pm 0.00$ & $1.59 \pm 0.00$ & $0.37 \pm 0.00$ \\
\hline \multicolumn{8}{|l|}{ Organic acids } \\
\hline Malic acid & nd & nd & $21.68 \pm 1.05$ & nd & $3.25 \pm 0.00$ & $21.09 \pm 0.03$ & $6.67 \pm 0.01$ \\
\hline Citric acid & $10.36 \pm 0.04$ & nd & nd & nd & nd & nd & nd \\
\hline Lactic acid & nd & nd & $101.44 \pm 4.92$ & $10.22 \pm 0.00$ & nd & nd & nd \\
\hline Succinic acid & nd & nd & $51.22 \pm 2.48$ & $10.54 \pm 0.00$ & $2.17 \pm 0.00$ & nd & nd \\
\hline Oxalic acid & $0.29 \pm 0.00$ & $4.34 \pm 0.00$ & $9.15 \pm 0.44$ & $5.47 \pm 0.00$ & $3.44 \pm 0.00$ & $4.35 \pm 0.01$ & $4.30 \pm 0.01$ \\
\hline Tartaric acid & nd & $5.83 \pm 0.00$ & nd & nd & nd & nd & $0.45 \pm 0.00$ \\
\hline Formic acid & nd & nd & $47.56 \pm 2.30$ & nd & nd & nd & nd \\
\hline Acetic acid & nd & $6.77 \pm 0.00$ & nd & nd & $1.85 \pm 0.00$ & $13.69 \pm 0.02$ & $5.12 \pm 0.01$ \\
\hline Propionic acid & nd & nd & nd & nd & nd & nd & $4.54 \pm 0.01$ \\
\hline Pyruvic acid & nd & nd & nd & nd & nd & nd & nd \\
\hline Ascorbic acid & nd & nd & nd & nd & $0.04 \pm 0.00$ & $7.31 \pm 0.01$ & $0.70 \pm 0.00$ \\
\hline Pyroglutamic acid & $0.27 \pm 0.00$ & nd & nd & nd & nd & $2.65 \pm 0.00$ & nd \\
\hline Total organic acids & $10.92 \pm 0.04$ & $16.94 \pm 0.00$ & $231.05 \pm 11.20$ & $26.23 \pm 0.01$ & $10.75 \pm 0.02$ & $49.09 \pm 0.06$ & $21.77 \pm 0.03$ \\
\hline
\end{tabular}

$n d$ not detected; the content was mean \pm standard deviation $(\mathrm{n}=3)$ 
was the highest in 20 pungent spices, followed by onion $(51.22 \mathrm{~g} / \mathrm{kg})$.

\section{Analysis of 5'-nucleotides}

The standard curves of four 5'-nucleotides were shown in Table 2. The 5'-nucleotide contents in 20 pungent spices were shown in Table 3. The content of 5'- nucleotide was more than $1 \mathrm{~g} / \mathrm{kg}$, including $5^{\prime}$-AMP in chive $(2.63 \mathrm{~g} / \mathrm{kg})$ and black mustard $(1.36 \mathrm{~g} / \mathrm{kg}), 5^{\prime}$-IMP in chilli $(1.07 \mathrm{~g} / \mathrm{kg})$. The 5'-GMP content $(0.47 \mathrm{~g} / \mathrm{kg})$ of prickly ash was the highest among 20 pungent spices, which accounted for $77.1 \%$ of the total 5'-nucleotide content in prickly ash.

Different 5'-nucleotides present different effects on food. 5'-IMP could increase the saltiness and acidity of products, whereas 5'-GMP could improve the smoothness and umami taste of products [34]. Mori et al. [35] reported that 5'-IMP and 5'-GMP were the main 5'-nucleotides. These findings were similar to those reported by Duan et al. [9] Moreover, 5 '-nucleotides could reduce the generation of unpleasant flavor during food processing [36]. Therefore, the amount of salt could be reduced by adding 5'-IMP and 5'-GMP or a mixture of them in food products, which will reduce the risk of diseases caused by excessive salt intake [37]. So the content of 5'-nucleotides have an important contribution to the taste of pungent spices.

\section{Analysis of TAV}

TAV is the ratio of the concentration of a flavoring substance in a sample $(C)$ to its taste threshold $(T)$.

$\mathrm{TAV}=C / T$.

It is considered that the substances with TAVs $>1$ have contribution to the flavor of samples. Therefore, the TAV can be used to determine the main flavor-producing substances of food samples [13, 38].

The TAVs of the 20 spices in this study were shown in Table 4. There are fourteen compounds with TAVs $>1$ in onion, twelve in garlic, eleven in prickly ash and horseradish respectively. However, only the TAVs of citric acid was greater than 1 in asafoetida and welsh onion. Although lactic acid has higher taste threshold $(2.6 \mathrm{mg} / \mathrm{g})$, but it has TAVs $>1$ in 13 pungent spices because of its higher content.

\section{Analysis of the EUC}

Because of the synergistic effect of disodium nucleotides and sodium glutamate, Tsai et al. [ 39] and Phat et al. [40] used the following formula to calculate the monosodium glutamate (MSG) equivalent of spices [27]:

$\mathrm{EUC}(\mathrm{gMSG} / 100 \mathrm{~g})=\Sigma a_{i} \times b_{i}+1218\left(\Sigma a_{i} \times b_{i}\right)\left(\Sigma a_{j} \times b_{j}\right)$.

where, $a_{i}(\mathrm{~g} / 100 \mathrm{~g})$ and $a_{j}(\mathrm{~g} / 100 \mathrm{~g})$ are the concentration of the flavor amino acids and nucleotides, respectively; $b i$ and $b j$ are the relative umami coefficients of the flavor amino acids and nucleotides, respectively; the 1218 coefficient was based on the synergistic constant of their concentration. Using this formula, the taste of a $100 \mathrm{~g}$ sample can be expressed as an equivalent amount of sodium glutamate.

The flavor intensity of the mixed solution was converted into the equivalent MSG concentration, which was used to quantify the flavor intensity of the mixed solution [41].

The EUCs value of the 20 spices in this work were shown in Fig. 2. The EUCs of 14 pungent spices were more than 1, including garlic, chive, white mustard, white pepper, prickly ash, ginger, onion, winter leek, long pepper, black mustard, peppermint, chilli, horseradish, and fieldmint. The EUCs of fieldmint $(37.1 \mathrm{~g} \mathrm{MSG} / 100 \mathrm{~g})$ was the highest in all 20 pungent spices, followed by peppermint $(24.5 \mathrm{~g} \mathrm{MSG} / 100 \mathrm{~g})$ and horseradish (18.4 g MSG/100 g). The EUCs of 12 elegant spices were more than 1 , and 7 strong fragrance spices with EUC > $1[9,10]$. More than 30\% spices had significant flavor with the EUC $>1$.

\section{Cluster analysis of the $\mathbf{2 0}$ pungent spices}

Cluster analysis was performed to study the relationship between the taste compounds and different spices. The tree diagram of the 20 pungent spices was presented in Fig. 3. The ordinate is the number of samples, and the abscissa was the Euclidean distance, which is the relative distance of each category. When the squared Euclidian distance was 10-25, the 20 pungent spices in this work were classified into two categories: fieldmint and the other 19 spices, which have high reliability. It is similar to the cluster analysis result of 29 elegant spices and 18 strong fragrance spices [9, 10]. When the squared Euclidian distance was $>25$, the spices were in one category according to cluster analysis of the EUC in 3 spices.

\section{Conclusion}

The taste compounds including free amino acids, 5 '-nucleotides and organic acids were determined by HPLC in 20 pungent spices. According to the cluster analysis of EUC, the 20 pungent spices were divided into 2 categories. The 


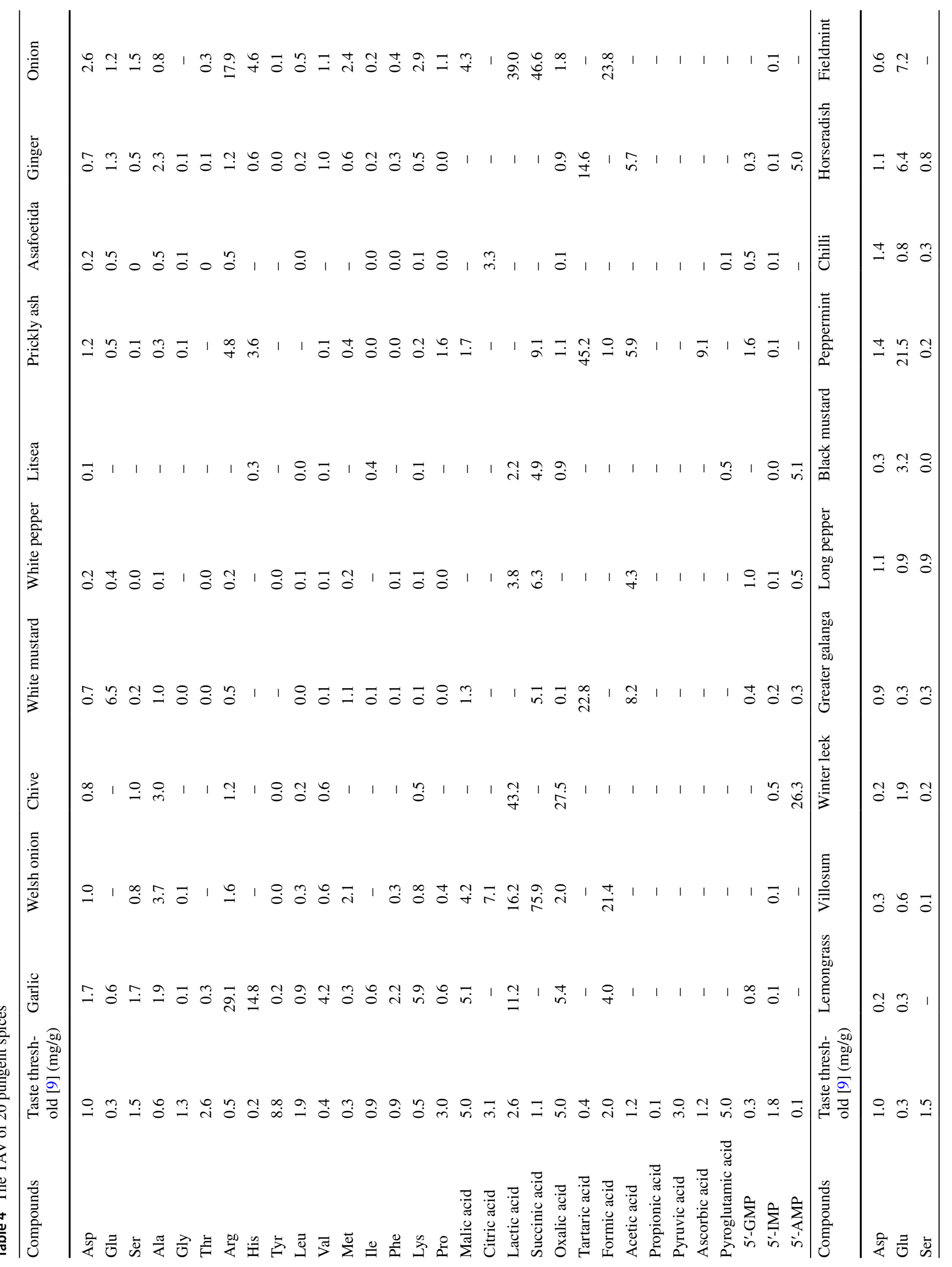




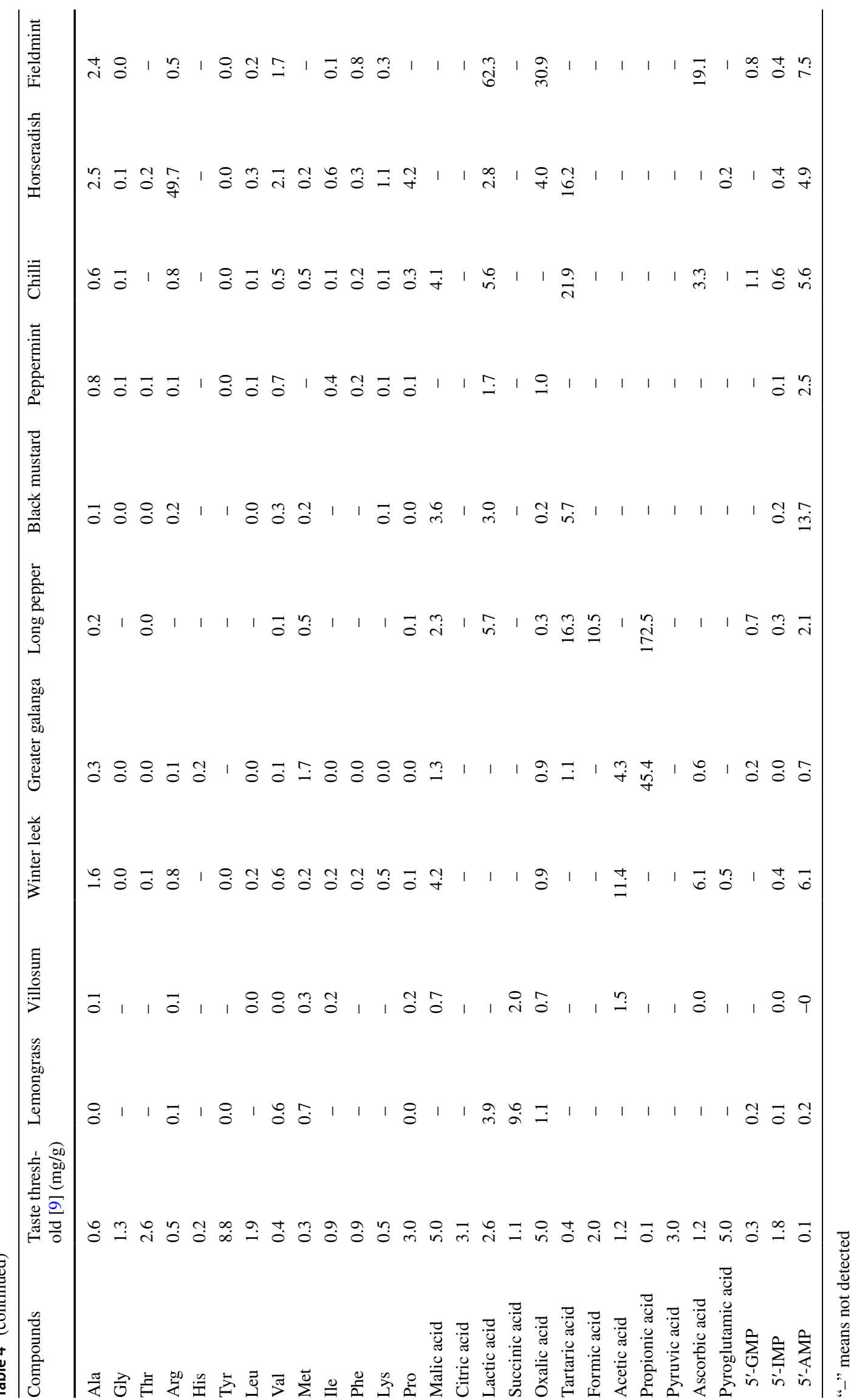




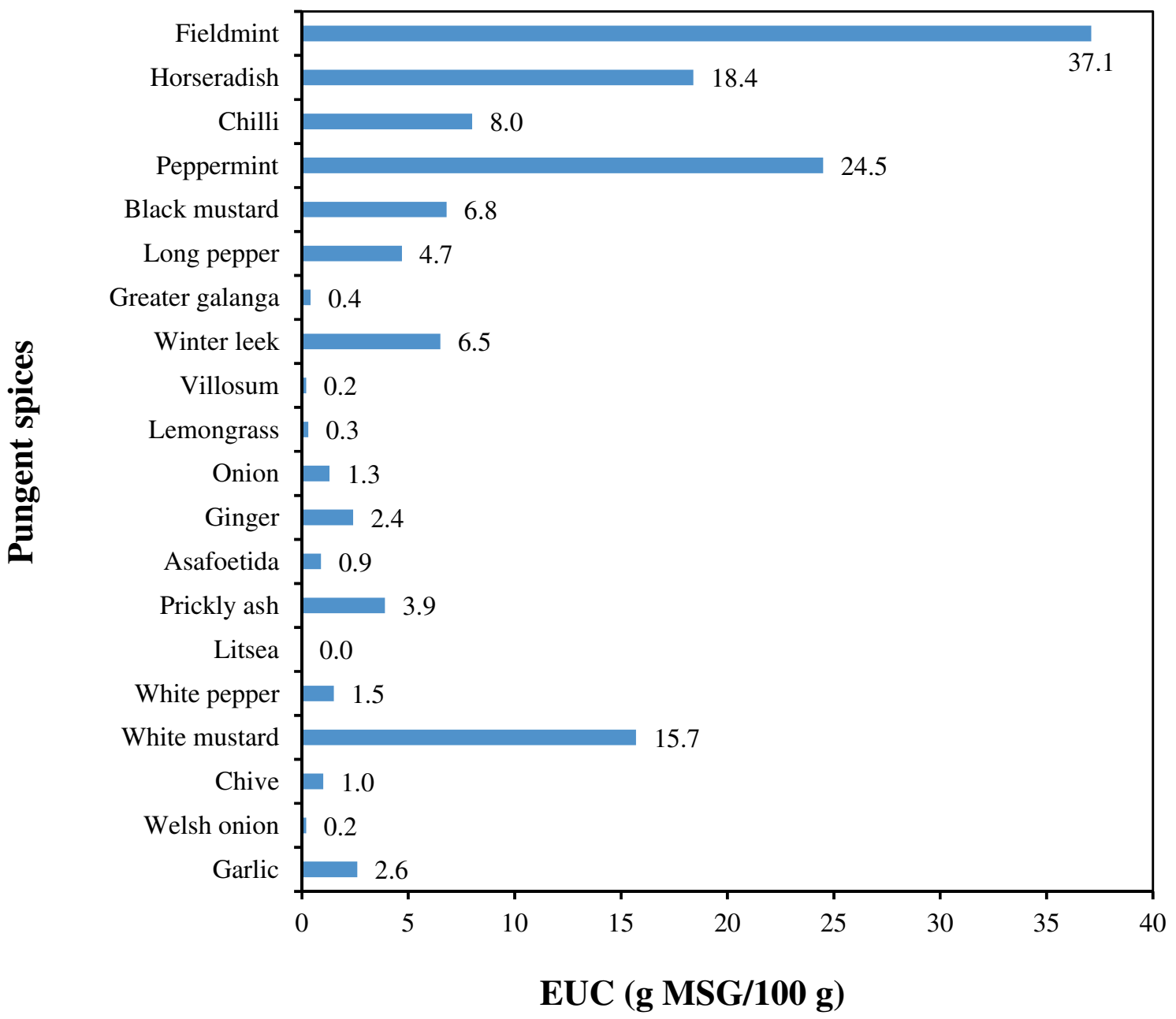

Fig. 2 The EUC of 20 pungent spices

fieldmint was one category, and the other 19 spices were another category. It means that the 20 pungent spices have similar umami taste. The total free amino acids of horseradish $(46.67 \mathrm{~g} / \mathrm{kg})$ were significantly higher than other 19 spices. Bitterness amino acids have higher content in 20 pungent spices, especially in litsea $(88.7 \%)$, horseradish
(86.3\%) and garlic (82.9\%). The total content of organic acids $(339.58 \mathrm{~g} / \mathrm{kg})$ in fieldmint was significantly higher than other 19 spices. 5'-IMP and 5'-GMP as the main umami 5'-nucleotides, have highest content in chilli (5'IMP) and prickly ash (5'-GMP). 


\section{Squared enclidean distance}

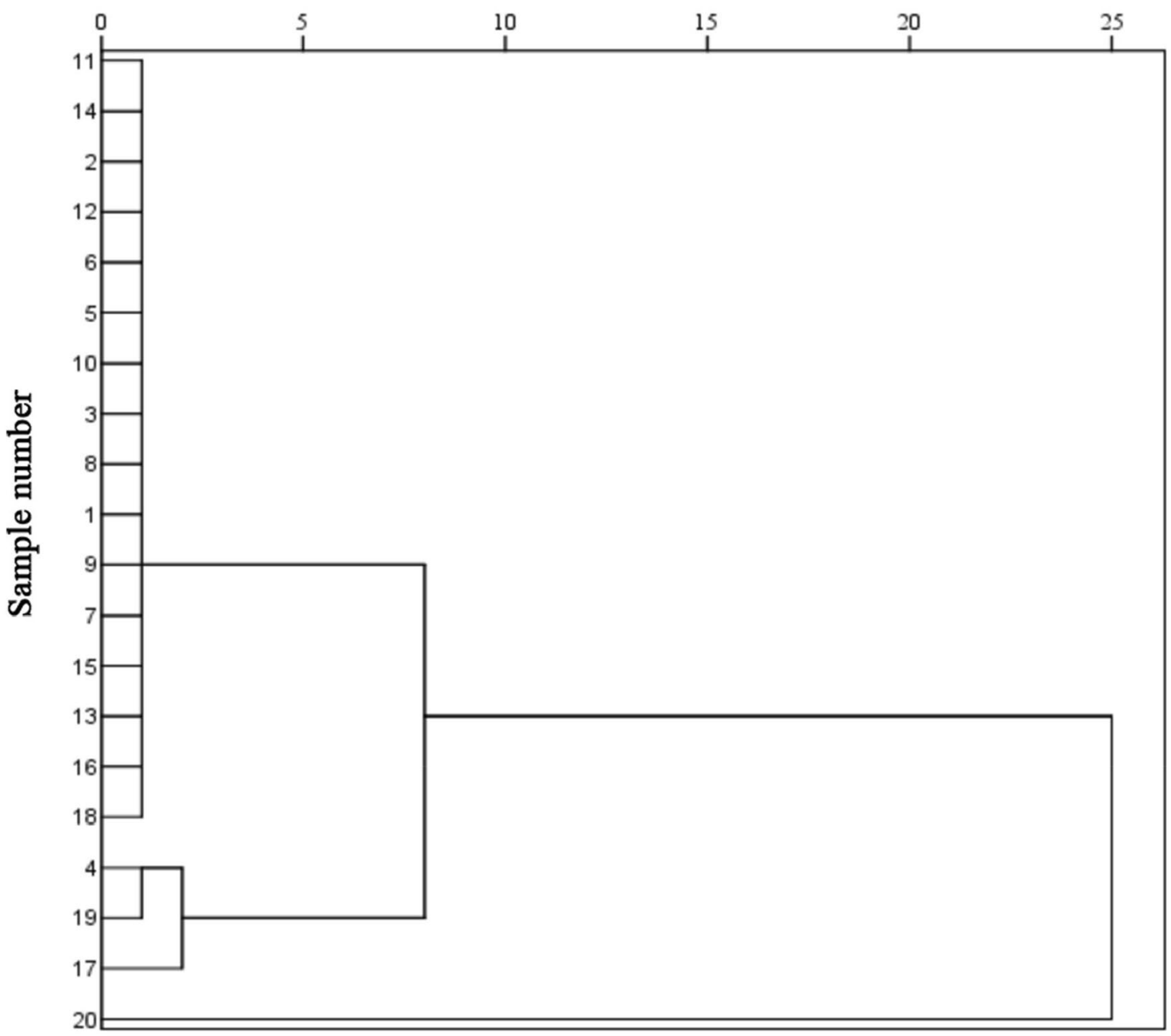

Fig. 3 Cluster analysis of pungent spices (1, Garlic; 2, Welsh onion; 3, Chive; 4, White mustar; 5, White pepper; 6, Litsea; 7, Prickly ash; 8, Asafoetida; 9, Ginger; 10, Onion; 11, Lemongrass; 12, Villosum;

Author contributions $\mathrm{YH}$ performed the experiments and collected the test data. HL and CZ drafted the manuscript. WD and JX analyzed the data. YZ designed the experiments and revised the manuscript. YT, BS, and ZL suggested amendments to the manuscript.

Funding This study was funded by the Beijing Outstanding Young Scientist Program (Grant Number BJJWZYJH01201910011025), the National Natural Science Foundation of China (Grant Number 31972191), and the School Level Cultivation Fund of Beijing Technology and Business University for Distinguished and Excellent Young Scholars (Grant Number BTBUYP2020).

\section{Compliance with ethical standards}

Conflict of interest The authors declare that they have no conflict of interest.
13, Winter leek; 14, Greater galangal; 15, Long pepper; 16, Black mustard; 17, Peppermint; 18, Chilli; 19, Horseradish; 20, Fieldmint)

Open Access This article is licensed under a Creative Commons Attribution 4.0 International License, which permits use, sharing, adaptation, distribution and reproduction in any medium or format, as long as you give appropriate credit to the original author(s) and the source, provide a link to the Creative Commons licence, and indicate if changes were made. The images or other third party material in this article are included in the article's Creative Commons licence, unless indicated otherwise in a credit line to the material. If material is not included in the article's Creative Commons licence and your intended use is not permitted by statutory regulation or exceeds the permitted use, you will need to obtain permission directly from the copyright holder. To view a copy of this licence, visit http://creativecommons .org/licenses/by/4.0/. 


\section{References}

1. H.B. Sowbhagya, P.F. Suma, S. Mahadevamma, R.N. Tharanathan, Food Chem. 104(3), 1220-1225 (2007)

2. P.D. Mbougueng, D. Tenin, C. Tchiégang, J. Scher, Am. J. Food Sci. Technol. 3, 33-39 (2015)

3. D.D. Pu, W. Duan, Y. Huang, L.L. Zhang, Y.Y. Zhang, B.G. Sun, F.Z. Ren, H.Y. Zhang, Y.Z. Tang, Food Chem. 339, 128078 (2020)

4. M.W. Schilling, A.J. Pham, J.B. Williams, Y.L. Xiong, N. Dhowlaghar, A.C. Tolentino, S. Kin, Meat Sci. 143, 199-209 (2018)

5. L.H. Wang, K.N. Qiao, W. Duan, Y.Y. Zhang, J.F. Xiao, Y. Huang, Food Sci. Nutr. 8(2), 955-964 (2020)

6. W. Duan, L.H. Wang, Y.Y. Zhang, Y. Huang, J.F. Xiao, D.D. $\mathrm{Pu}$, J. Food Process. Pres. 44(5), e14425 (2020)

7. Y. Yoshihisa, I. Kazumi, M. Motoki, Y. Akihiro, Food Sci. Technol. Res. 17(1), 55-62 (2011)

8. N. Zhang, B.G. Sun, X.Y. Mao, H.T. Chen, Y.Y. Zhang, Food Res. Int. 121, 296-306 (2019)

9. W. Duan, Y. Huang, J. Xiao, Y. Zhang, H. Zhang, Int. J. Food. Prop. 23, 340-353 (2020)

10. W. Duan, Y. Huang, J.F. Xiao, Y.Y. Zhang, Y.Z. Tang, Food Sci. Nutr. 8(7), 3777-3792 (2020)

11. M. Pirsaheb, N. Fattahi, RSC Adv. 8, 11412-11418 (2018)

12. R. Akramipour, M.R. Golpayegani, S. Gheini, N. Fattahi, Talanta 186, 17-23 (2018)

13. M.H. Habibollahi, K. Karimyan, H. Arfaeinia, N. Mirzaei, Y. Safari, R. Akramipour, H. Sharafi, N. Fattahi, J. Sci. Food Agric. 99(2), 656-665 (2019)

14. R. Akramipour, M.R. Golpayegani, M. Ghasemi, N. Noori, N. Fattahi, New J. Chem. 43, 6951-6958 (2019)

15. M. Karmaei, K. Sharafi, M. Moradi, H.R. Ghaffari, H. Biglari, H. Arfaeinia, N. Fattahi, Anal. Methods 9(19), 2865-2872 (2017)

16. M. Pirsaheb, N. Fattahi, M. Shamsipur, T. Khodadadi, J. Sep. Sci. 36, 684-689 (2013)

17. M. Ataee, T. Ahmadi-Jouibari, N. Fattahi, Int. J. Environ. Anal. Chem. 96(3), 271-283 (2016)

18. M. Rezaee, F. Khalilian, H.A. Mashayekhi, N. Fattahi, Anal. Methods 6(10), 3456-3461 (2014)

19. M. Sadeghi, Z. Nematifar, M. Irandoust, N. Fattahi, P. Hamzei, A. Barati, M. Ramezani, M. Shamsipur, RSC Adv. 5(122), 100511100521 (2015)

20. Y. Yang, Q.Q. Chen, C. Shen, S.M. Zhang, Z.L. Gan, R. Hu, J.H. Zhao, Y.Y. Ni, J. Food Eng. 116(3), 627-632 (2013)
21. Y. Kong, L.L. Zhang, Y. Sun, Y.Y. Zhang, B.G. Sun, H.T. Chen, J. Food Sci. 82, 1116-1123 (2017)

22. Y. Kong, L.L. Zhang, Y.Y. Zhang, B.G. Sun, Y. Sun, J. Zhao, H.T. Chen, Int. J. Food Prop. 21, 1854-1866 (2018)

23. T. Fujita, S. Komemushi, K. Yamagata, J. Sci. Food Agric. 55(1), 159-162 (1991)

24. Y. Kong, X. Yang, Q. Ding, Y.Y. Zhang, B.G. Sun, H.T. Chen, Y. Sun, Food Res. Int. 102, 559-566 (2017)

25. A. Shafaei, N.H.A. Halim, N. Zakaria, Z. Ismail, Pharmacogn. Mag. 13, S385-S391 (2017)

26. C.L. Yang, X.M. Jiang, L.Y. Guo, H.X. Zhang, M.C. Liu, J. Sep. Sci. 30(18), 3154-3163 (2007)

27. X. Yang, Y.Y. Zhang, Y. Kong, J. Zhao, Y. Sun, M.Q. Huang, Int. J. Food Prop. 22, 1100-1111 (2019)

28. Y. Kani, N. Yoshikawa, S. Okada, H. Abe, Fish Sci. 73, 940-949 (2007)

29. Y. Kim, E.Y. Kim, H.J. Son, J.J. Lee, Y.H. Choi, M.R. Rhyu, Food Chem. 233, 256-262 (2017)

30. D.H. Daniels, F.L. Joe Jr., G.W. Diachenko, FoodAddit. Contam. 12, 21-29 (1995)

31. D.W. Chen, M. Zhang, Food Chem. 104(3), 1200-1205 (2007)

32. V. Pereira, F.M. Albuquerque, A.C. Ferreira, J. Cacho, J.C. Marques, Food Res. Int. 44(1), 71-76 (2011)

33. A. Istiqamah, H.N. Lioe, D.R. Adawiyah, Food Chem. 270, 338 343 (2019)

34. M. Kochem, P.A.S. Breslin, PLoS ONE 12(3), e0172534 (2017)

35. T. Mori, K. Iseki, J. Teeter, D. Restrepo, Y. Hayashi, S.H. Oh, Sensory Neuron. 3(3), 155-167 (2001)

36. L. Kong, C.F. Cai, Y.T. Ye, D.X. Chen, P. Wu, E.C. Li, L.Q. Chen, L. Song, Aquaculture 364, 96-102 (2012)

37. S. Han, D.L. Cheng, N.J. Liu, H.Y. Kuang, J. Diabetes Complicat. 32, 531-537 (2018)

38. D.D. Pu, Y.Y. Zhang, B.G. Sun, F.Z. Ren, H.Y. Zhang, H.T. Chen, Y.Z. Tang, LWT 138, 110641 (2020)

39. S.Y. Tsai, H.L. Tsai, J.L. Mau, Food Chem. 107(3), 977-983 (2008)

40. C. Phat, B.K. Moon, C. Lee, Food Chem. 192, 1068-1077 (2016)

41. P.D. Chiang, C.T. Yen, J.L. Mau, Food Chem. 101(3), 932-937 (2007)

Publisher's Note Springer Nature remains neutral with regard to jurisdictional claims in published maps and institutional affiliations. 